\title{
Níveis de treonina digestível para suínos machos castrados, de alto potencial genético para deposição de carne, na fase de terminação
}

[Digestible threonine levels for high genetic potential lean deposition finishing barrows]

\author{
M.C. Rossoni ${ }^{1}$, J.L. Donzele ${ }^{1}$, R.F.M. Oliveira ${ }^{1}$, F.C.O. Silva ${ }^{2}$, M.L.T. Abreu ${ }^{1}$, J.L. Kill ${ }^{3}$, \\ A.S. Fereira ${ }^{4}$, G. Gattás \\ ${ }^{1}$ Departamento de Zootecnia - UFV \\ Av. P. H. Rolfs, s/n \\ 36571-000 -- Viçosa, MG \\ ${ }^{2}$ EPAMIG - Viçosa, MG \\ ${ }^{3}$ Departamento de Zootecnia - UFPI - Teresina, PI \\ ${ }^{4}$ Departamento Zootecnia - UVV - Vila Velha, ES \\ ${ }^{5}$ Aluno de graduação - UFV - Viçosa, MG
}

\begin{abstract}
RESUMO
Avaliou-se o efeito de níveis de treonina digestível em rações sobre o desempenho e características de cacaça de suínos machos castrados, selecionados geneticamente, para deposição de carne na carcaça, na fase de terminação. Foram utilizados 70 animais, com peso inicial de $59,00 \pm 1,25 \mathrm{~kg}$, distribuídos em delineamento experimental de blocos ao acaso, com cinco tratamentos, sete repetições e dois animais por unidade experimental, sendo que na distribuição dos animais, foi adotado como critério o peso inicial. Os tratamentos foram níveis de treonina na ração $(0,480 ; 0,504 ; 0,528 ; 0,554$ e $0,572 \%$ de treonina digestível). Não houve efeito $(\mathrm{P}>0,05)$ dos tratamentos sobre o ganho de peso, consumo de ração e conversão alimentar. Os níveis de treonina digestível não influenciaram $(\mathrm{P}>0,05)$ a porcentagem de carne e a espessura de toucinho na carcaça. Conclui-se que o nível de $0,480 \%$ de treonina digestível, correspondente a relação de treonina digestível:lisina digestível de $60 \%$, atendeu as exigências de suínos machos castrados de alto potencial para deposição de carne na carcaça dos 60 aos $95 \mathrm{~kg}$.
\end{abstract}

Palavras-chave: suíno, aminoácido, carcaça, genótipo, proteína ideal, terminação

\begin{abstract}
An experiment was carried out to determine the effects of digestible threonine levels in ration on the performance and carcass traits of hogs genetically selected for lean deposition at finishing. Seventy barrows averaging an initial weight of $59.00+1.25 \mathrm{~kg}$ were distributed in a randomized experimental block design with five treatments and seven replicates, being two animals per experimental unit. Initial weight was adopted as a criterion for animal distribution in the treatments, which were the levels of digestible treonine in the diet (0.480; 0.504; 0.528; 0.554; and 0.572\%). No effect $(P>0.05)$ was observed among the treatments on daily weight gain, daily feed intake, and feed conversion. Digestible threonine levels did not influence (P>0.05) lean and backfat thickness percentage. It can be concluded that the level of $0.480 \%$ of digestible treonine, corresponding to the rate digestible treonine:lysine $60 \%$, supplied the requirments of high potential lean deposition barows from 60 to $95 \mathrm{~kg}$.
\end{abstract}

Keywords: swine, amino acid, carcass, genotype, ideal protein, nutritional requeriment

\section{INTRODUÇ̃̃O}

A seleção de suínos para maior deposição de proteína em relação à de gordura na carcaça tem resultado na necessidade de reavaliação das

Recebido em 10 de maio de 2007

Aceito em 14 de abril de 2008

E-mail: mariana@rossoniseguros.com.br exigências nutricionais dessa espécie nas diferentes fases do ciclo de produção. Nas fases de crescimento e terminação, quando ocorre maior deposição de tecido magro, mudanças nas taxas de deposição de tecido pode proporcionar diferenças ainda mais significativas na exigência de nutrientes. 
Entretanto, é preciso considerar que o desempenho animal pode ser influenciado pelo balanço de aminoácidos. Além disso, o balanço de aminoácidos tem sido considerado como um dos principais fatores envolvidos na alimentação de suínos, devido ao fato de, quando utilizado apropriadamente, possibilitar aos animais rápido crescimento e maior deposição de carne (Henry e Sève, 1998).

Sabe-se que a treonina é um aminoácido que desempenha importante função na mantença do animal e pode ser considerada como segundo ou terceiro aminoácido limitante em rações para suínos formuladas a base de cevada e farelo de trigo (De Blas et al., 2004), podendo tornar-se, contudo, o primeiro limitante quando lisina sintética for adicionada às rações (Saldana et al., 1994).

Tem-se observado efeito negativo do excesso de treonina sobre o consumo alimentar e a deposição de gordura nos suínos. $\mathrm{O}$ acúmulo de treonina no sangue, a dificuldade de oxidação do excesso de treonina e a redução da secreção de seretonina no cérebro, em razão do aumento da concentração de treonina (Sève e Henry, 1998), induziriam uma diminuição da ingestão de alimentos. Assim, a exigência de treonina para máximo crescimento do tecido magro seria maior que aquela estabelecida para máximo ganho de peso (De Blas et al., 2004). O nível protéico das rações, os sistemas de alimentação, a capacidade genética dos suínos, o sexo e a relação entre aminoácidos limitantes podem, entretanto, influenciar a exigência de treonina para suínos nas diferentes fases do ciclo produtivo (Ajinomoto, 2000). Dentre esses fatores, faz-se necessário determinar a exigência para os diferentes sexos, uma vez que machos castrados consomem mais alimento e ganham peso mais rapidamente que as marrãs. As fêmeas, por outro lado, são mais eficientes em converter alimento em ganho de peso em valores relativos e depositam maior porcentagem de tecido muscular e menor de tecido adiposo que os machos castrados. A maior deposição de tecido magro e o menor consumo em relação aos machos faz com que as fêmeas tenham a exigência em aminoácido maior que os machos castrados (Pozza, 1997).

As exigências de treonina, determinadas com suínos machos castrados, selecionados geneticamente para deposição de carne na carcaça, com base na taxa de acúmulo de proteína ou na capacidade do suíno em produzir carcaça, são limitadas. Assim, o trabaho teve o objetivo de avaliar níveis de treonina digestível para suínos machos castrados, selecionados para deposição de carne na carcaça, na fase de terminação.

\section{MATERIAL E MÉTODOS}

O experimento foi realizado na Granja de Suínos da Fazenda Experimental Vale do Piranga, de propriedade da EPAMIG, em novembro a dezembro de 2003.

Foram utilizados 70 suínos machos castrados selecionados para deposição de carne na carcaça, com peso inicial de $59,00 \pm 1,25 \mathrm{~kg}$, distribuídos em delineamento experimental de blocos ao acaso, com cinco tratamentos, sete repetições e dois animais por unidade experimental. $\mathrm{Na}$ distribuição dos animais, foi adotado como critério o peso inicial. Os tratamentos foram cinco níveis de treonina: 0,$480 ; 0,504 ; 0,528 ; 0,554$ e $0,572 \%$ de treonina digestível.

Os animais foram alojados em baias providas de comedouro semi-automático e bebedouros. As rações experimentais (Tab. 1) foram formuladas à base de milho e farelo de soja, para atender às exigências nutricionais dos animais de acordo com Rostagno et al. (2000), exceto a treonina. As relações aminoacídicas entre a lisina digestível e os demais aminoácidos essenciais digestíveis foram estabelecidas a partir de valores mínimos propostos por Rostagno et al. (2000) para suínos em terminação, a fim de se assegurar que somente a treonina estivesse limitante na ração.

Ração e a água foram fornecidas à vontade. As rações foram isoenergéticas, isoprotéicas $\mathrm{e}$ isolisínicas. As relações treonina digestível:lisina digestível foram obtidas com a suplementação de L-treonina, adição em substituição proporcional ao ácido glutâmico, com base no equivalente protéico, a fim de manter as rações isonitrogenadas, com a adição de amido.

Ao final do período experimental, quando atingiram o peso de $95,00 \pm 0,97 \mathrm{~kg}$, os animais foram submetidos a jejum alimentar por 18 horas, novamente pesados, e posteriormente encaminhados ao frigorífico comercial. $\mathrm{O}$ abate foi realizado por atordoamento elétrico e sangramento e em seguida, os animais foram depilados com lança-chamas e eviscerados. Nas carcaças foram aferidos rendimento de carne e espessura de toucinho por meio de aparelho de tipificação de carcaça ${ }^{1}$.

${ }^{1}$ GP-4 Henessy - Solft Didai - Nova Zelândia. 
Tabela 1. Composição centesimal e calculada das rações experimentais utilizadas para suínos

\begin{tabular}{|c|c|c|c|c|c|}
\hline \multirow{2}{*}{ Ingrediente } & \multicolumn{5}{|c|}{ Nível de treonina digestível (\%) } \\
\hline & 0,480 & 0,504 & 0,528 & 0,552 & 0,576 \\
\hline Milho & 77,511 & 77,511 & 77,511 & 77,511 & 77,511 \\
\hline Farelo de soja & 18,384 & 18,384 & 18,384 & 18,384 & 18,384 \\
\hline Fosfato bicálcico & 1,232 & 1,232 & 1,232 & 1,232 & 1,232 \\
\hline Calcário & 0,618 & 0,618 & 0,618 & 0,618 & 0,618 \\
\hline Óleo de soja & 0,820 & 0,820 & 0,820 & 0,820 & 0,820 \\
\hline BHT & 0,010 & 0,010 & 0,010 & 0,010 & 0,010 \\
\hline Sal & 0,314 & 0,314 & 0,314 & 0,314 & 0,314 \\
\hline Suplemento vitamínico ${ }^{1}$ & 0,300 & 0,300 & 0,300 & 0,300 & 0,300 \\
\hline Suplemento mineral $^{2}$ & 0,100 & 0,100 & 0,100 & 0,100 & 0,100 \\
\hline L-lisina & 0,250 & 0,250 & 0,250 & 0,250 & 0,250 \\
\hline DL-metionina & 0,094 & 0,094 & 0,094 & 0,094 & 0,094 \\
\hline L-treonina & 0,000 & 0,027 & 0,053 & 0,080 & 0,106 \\
\hline L-triptofano & 0,017 & 0,017 & 0,017 & 0,017 & 0,017 \\
\hline Amido & 0,200 & 0,206 & 0,213 & 0,219 & 0,225 \\
\hline Ácido glutâmico & 0,150 & 0,117 & 0,084 & 0,051 & 0,019 \\
\hline Total & 100,00 & 100,00 & 100,00 & 100,00 & 100,00 \\
\hline \multicolumn{6}{|l|}{ Composição calculada $^{3}$} \\
\hline Energia digestível (kcal/kg) & 3400 & 3400 & 3400 & 3400 & 3400 \\
\hline Proteína bruta $(\%)$ & 15,414 & 15,414 & 15,414 & 15,414 & 15,414 \\
\hline Lisina total $(\%)$ & 0,901 & 0,901 & 0,901 & 0,901 & 0,901 \\
\hline Lisina digestível (\%) & 0,800 & 0,800 & 0,800 & 0,800 & 0,800 \\
\hline Treonina total $(\%)$ & 0,583 & 0,610 & 0,635 & 0,662 & 0,688 \\
\hline Treonina digestível $(\%)$ & 0,480 & 0,504 & 0,528 & 0,552 & 0,576 \\
\hline Metionina+cistina digestível (\%) & 0,560 & 0,560 & 0,560 & 0,560 & 0,560 \\
\hline Isoleucina digestível (\%) & 0,536 & 0,536 & 0,536 & 0,536 & 0,536 \\
\hline Triptofano digestível (\%) & 0,160 & 0,160 & 0,160 & 0,160 & 0,160 \\
\hline Cálcio (\%) & 0,65 & 0,65 & 0,65 & 0,65 & 0,65 \\
\hline Fósforo disponível (\%) & 0,32 & 0,32 & 0,32 & 0,32 & 0,32 \\
\hline Relação treonina:lisina digestíveis (\%) & 0,60 & 0,63 & 0,66 & 0,69 & 0,72 \\
\hline
\end{tabular}

${ }^{\mathrm{T}}$ Quantidade kg/ração= vit.A: 10.000.000UI; vit.D ${ }_{3}$ : 1.000.000UI; vit.E: 15.000 UI; vit.K3: 25g; vit.C: 30g; Tiamina: $3 \mathrm{~g}$; riboflavina: 1,5g; vit. B12: 22mg; ácido pantotênico: $12 \mathrm{~g}$; ácido fólico:b0,6g; Biotina: 0,1g; antioxidante: $30 \mathrm{~g}$; excipiente qsp. $500 \mathrm{~g}$.

${ }^{2}$ Quantidade kg/ração= Fé: $90 \mathrm{~g}$; Cu: 10g; Mn: 40g; Zn: 2g; excipiente qsp 500g.

${ }^{3}$ Segundo Rostagno et al. (2000).

Foram avaliados o ganho de peso diário (GPD), o consumo de ração diário (CRD), a conversão alimentar (CA), o consumo diário de treonina digestível (CTD), a espessura de toucinho no ponto $\mathrm{P}_{2}$ e o rendimento de carne. O modelo estatístico utilizado foi:

$\mathrm{Y}_{\mathrm{ijk}}=\mu+\mathrm{B}_{\mathrm{i}}+\mathrm{T}_{\mathrm{j}}+\mathrm{e}_{\mathrm{ijk}}$, em que:

$\mathrm{Y}_{\mathrm{ijk}}=$ característica observada

$\mu=$ média geral das características;

$\mathrm{B}_{\mathrm{i}}=$ efeito do bloco $\mathrm{i} ; \mathrm{i}=1,2,3,4$ e 5;

$\mathrm{T}_{\mathrm{j}}=$ efeito do nível de treonina $\mathrm{j} ; \mathrm{j}=1,2$, 3,4 e 5 ;

$\mathrm{e}_{\mathrm{ijk}}=$ erro aleatório associado a cada observação.

As variáveis de desempenho e de carcaça foram analisadas pelo SAEG (Sistema ..., 2000), utilizando-se os procedimentos para análises de variância e regressão. As estimativas de exigência de treonina digestível e a sua relação com a lisina digestível foram determinadas por meio de análises de regressão linear, quadrática e/ou descontínuo linear response plateau (LRP), conforme o melhor ajustamento obtido para cada variável, levando em consideração o comportamento biológico dos animais.

Durante o período experimental, a temperatura mínima e máxima do ar do galpão foram de $20,5+2,71^{\circ} \mathrm{C}$ a $31,7+3,16^{\circ} \mathrm{C}$, respectivamente.

\section{RESULTADOS E DISCUSSÃO}

Os resultados de ganho de peso médio diário, consumo de ração médio diário, conversão alimentar, consumo de treonina digestível diário, espessura de toucinho no ponto $\mathrm{P}_{2}$ e rendimento de carne na carcaça de suínos machos castrados, dos 60 aos $95 \mathrm{~kg}$, consumindo diferentes níveis de treonina encontram-se na Tab. 2. 
Não se observou efeito $(\mathrm{P}>0,05)$ dos níveis de treonina digestível sobre o GPD dos animais, indicando que o menor nível de treonina digestível de $0,48 \%$ avaliado neste estudo, que correspondeu a uma relação de $60 \%$ de treonina digestível:lisina digestível, foi suficiente para que se registrasse nos animais o máximo potencial de crescimento. Resultado semelhante foi obtido por Lenis et al. (1990) que também não verificaram variação significativa no GPD de suínos na fase de terminação (60 a $95 \mathrm{~kg})$ em razão do aumento no nível de treonina digestível da ração entre 0,32 e $0,50 \%$.

Tabela 2. Desempenho e características de carcaça de suínos machos castrados de alto potencial para deposição de carne, dos 60 aos $95 \mathrm{~kg}$, em função dos níveis de treonina digestível da ração

\begin{tabular}{lcccccc}
\hline \multirow{2}{*}{\multicolumn{1}{c}{ Variável }} & \multicolumn{4}{c}{ Nível de treonina digestível $(\%)$} & $\mathrm{CV}$ \\
\cline { 2 - 7 } & 0,480 & 0,504 & 0,528 & 0,552 & 0,576 & $(\%)$ \\
\hline Ganho de peso diário $(\mathrm{kg})$ & 1,11 & 1,16 & 1,17 & 1,10 & 1,12 & 6,21 \\
Consumo de ração diário $(\mathrm{kg})$ & 2,77 & 2,87 & 3,01 & 2,79 & 2,82 & 7,33 \\
Conversão alimentar (kg/kg) & 2,49 & 2,47 & 2,57 & 2,54 & 2,52 & 6,84 \\
Consumo de treonina digestível diário $(\mathrm{g})^{1}$ & 13,29 & 14,47 & 15,88 & 15,41 & 16,26 & 7,48 \\
Espessura de toucinho P2 (mm) & 10,58 & 11,56 & 9,88 & 12,25 & 11,91 & 21,20 \\
Rendimento de Carne (\%) & 58,57 & 57,52 & 58,34 & 57,52 & 57,68 & 2,94 \\
\hline
\end{tabular}

${ }^{1}$ Efeito linear $(\mathrm{P}<0,05)$

Embora Saldana et al. (1994), Schutte et al. (1997) e Ettle et al. (2004), em estudos com suínos em terminação, tenham observado influência dos níveis de treonina digestível sobre o GPD, os níveis em que foram obtidas as melhores respostas, que corresponderam, respectivamente, a $0,297,0,280,0,360$ e $0,350 \%$, ficaram consistentemente abaixo do menor nível avaliado neste estudo, o que confirma a coerência dos resultados obtidos.

O CRD dos animais não foi influenciado $(\mathrm{P}>0,05)$ pelos níveis de treonina digestível da ração. De forma similar, Lenis et al. (1990), Schutte et al. (1997) e Ettle et al. (2004) também não verificaram variação significativa no consumo voluntário de alimento dos suínos na fase de terminação em razão do aumento do nível de treonina da ração. Saldana et al. (1994) ao avaliarem os níveis de treonina entre 0,30 e 0,50\% para suínos dos 58 aos $96 \mathrm{~kg}$, observaram efeito quadrático dos tratamentos sobre o consumo de ração, que reduziu nos dois maiores níveis $(0,45$ e $0,50 \%)$ de treonina avaliados.

Os dados de CRD obtidos neste estudo não confirmam o relato de Henry e Sève (1998), de que suínos selecionados geneticamente para maior deposição de carne são mais sensíveis ao desequilíbrio de aminoácidos da ração, principalmente de treonina, triptofano e metionina, reduzindo o consumo voluntário de ração. Também não confirmam o estudo de De Blas et al. (2004), de que a baixa capacidade de oxidação do excesso de treonina plasmática pelos suínos teria reflexo negativo sobre o consumo voluntário de alimento desses animais.

Os níveis de treonina digestível não influenciaram $(\mathrm{P}>0,05)$ a $\mathrm{CA}$, evidenciando que o nível de $0,48 \%$ de treonina digestível na ração, correspondente a uma relação de $60 \%$ com a lisina digestível, foi suficiente também para maximizar a eficiência de utilização do alimento para ganho de peso dos suínos.

Ettle et al. (2004), ao avaliarem os níveis de treonina digestível, com variação de 0,32 a $0,44 \%$, para suínos dos 50 aos $95 \mathrm{~kg}$, verificaram melhora na CA dos animais somente entre os níveis de 0,32 e $0,37 \%$, correspondentes a relações, respectivamente, de 49 e $56 \%$ com a lisina digestível.

Perdesen et al. (2003), ao investigarem o efeito da relação treonina e lisina digestíveis, para suínos em terminação, concluíram que o melhor resultado foi obtido com a relação de $64 \%$.

A divergência de resultados observados pode ser explicada, em parte, pela variação na composição das rações experimentais utilizadas, assim como pelas condições ambientais, com relação ao grau de desafio imunológico a que os animais foram expostos durante a realização dos experimentos.

Com relação à composição da ração, estudos realizados com suínos por Zhu et al. (2005) evidenciaram que a utilização da treonina 
digestível para deposição de proteína diminuiu à medida que se aumentou o nível de polissacarídeos não amiláceos solúveis (pectina) na ração. Quanto ao desafio imunológico, Defa et al. (1999) concluíram que a treonina está envolvida na função imune, e que o nível necessário para maximizar a resposta imune é maior que para maximizar o ganho de peso dos suínos.

A relação treonina digestível:lisina digestível de $60 \%$, que atendeu a demanda dos animais neste estudo, ficou abaixo das recomendações das tabelas, nacional e internacional, de exigência para suínos em terminação. Enquanto o NRC (Nutrient..., 1998) preconiza uma relação de treonina digestível:lisina digestível para suínos machos castrados de alto potencial genético para deposição de carne, na fase de terminação, de $64 \%$, as recomendações contidas nas Tabelas Brasileiras de Exigências Nutricionais (Rostagno et al., 2000) e do INRA (L'alimentation..., 1989) para suínos da mesma categoria, foram de $67 \mathrm{e}$ $70 \%$, respectivamente.

O consumo diário de treonina digestível aumentou $(\mathrm{P}<0,05)$ de forma linear, segundo a equação $\hat{Y}=158,965-157,455 X\left(r^{2}=0,98\right)$, em razão do acréscimo de treonina na ração. Vista a ausência de variação significativa do CRD, o aumento na ingestão diária de treonina digestível ocorreu em razão direta de sua concentração nas rações, indicando que o consumo estimado de 13,30g de treonina/dia atendeu as exigências dos suínos de alto potencial para deposição de carne em terminação para melhor desempenho. Essa demanda de treonina ficou acima dos 11,0 e $10,7 \mathrm{~g} /$ dia preconizados, respectivamente, pelo NRC (Nutrient..., 1998) e por Ettle et al. (2004) para esta categoria animal

As variações de resultados entre os estudos podem ser atribuídas a diferenças na genética dos animais utilizados nos experimentos, quanto a capacidade de deposição de proteína na carcaça dos animais. De acordo com os resultados de Thong e Liebert (2004) obtidos com suínos de $50 \mathrm{~kg}$, a exigência de treonina aumentou de $8,96 \mathrm{~g}$ para $12,20 \mathrm{~g}$ quando a capacidade de deposição de proteína variou de 130 para $160 \mathrm{~g} / \mathrm{dia}$.

Com relação às características de carcaça verificou-se que os tratamentos não influenciaram $(\mathrm{P}>0,05)$ a porcentagem de carne na carcaça e a espessura de toucinho no ponto $\mathrm{P}_{2}$. De maneira similar, Pedersen et al. (2003) e Ettle et al. (2004) não verificaram variação significativa na espessura de toucinho e na porcentagem de carne na carcaça de suínos em terminação com a elevação do nível de treonina da ração.

Este resultado confirma os relatos de Lenis e Van Diepen (1990), Lenis et al. (1990), Schutte et al. (1997) e Ettle et al. (2004), de que não há efeito significativo do nível de treonina na ração sobre o rendimento de carne e a espessura de toucinho de suínos em terminação, ou seja, o efeito da suplementação de treonina sobre as características de carcaça tem sido menor do que a influência sobre o desempenho animal.

\section{CONCLUSÃO}

O nível de $0,480 \%$ de treonina digestível, correspondente à relação de treonina digestível:lisina digestível de $60 \%$ a um consumo diário de $13,30 \mathrm{~g}$ de treonina digestível, atendeu às exigências de suínos machos castrados de alto potencial para deposição de carne na fase de terminação para melhor desempenho e características de carcaça.

\section{REFERÊNCIAS BIBLIOGRÁFICAS}

AJINOMOTO, 2000. Disponível em: $<$ http://www.lisina.com.br/upload/bibliografia/rp 20.pdf.> Acessado em: 10 jun. 2004.

DE BLAS, C.; GARCIA, A.I.; CARABAÑO, R. Necesidades de treonina en animales monogástricos. In: CURSO DE ESPECIALIZACIÓN NECESIDADES DE TREONINA EN ANIMALES MONOGÁSTRICOS, 16., 2004, Madrid. Anais... Madrid: Universidad Politécnica de Madrid, 2004. p.22.

DEFA, L.; CHANGTING, X.; SHIYAN, Q. et al. Effects of dietary threonine on performance, plasma parameters and immune function of growing pigs. Anim. Feed Sci. Tech., v.78, p.179-188, 1999.

ETTLE, T.; ROTH-MAIER, D.A.; BARTELT, J. et al. Requirement of true ileal digestible threonine of growing and finishing pigs. J. Anim. Phys. Anim. Nutr., v.88, p.211-222, 2004. 
HENRY, Y.; SÈVE, B. Feed intake and dietary amino acid balance in growing pigs with special reference to lysine, tryptophan, and threonine. Pig News Prod. Anim., v.1, p.65-74, 1998

L'ALIMENTATION des animaux monogastriques: porc, lapin, volaillles. 2.ed. Paris: Institute National de la Recherche Agronomique, 1989

LENIS, N.P.; VAN DIEPEN, J.T.M.; GOEGHART, P.W. Amino acid requirement of pigs. 1. Requirement for methionine + cystine, threonine and tryptophan of fast-growing boars and gilts, fed ad libitum. Netherl. J. Agric. Sci., v.38, p.577-595, 1990.

LENIS, N.P.; VAN DIEPEN, J.T.M. Amino acid requirement of pigs. 3. Requirement for apparent digestible threonine of pigs in different stages of growth. Netherl. J. Agric. Sci., v.38, p.609-622, 1990.

NUTRIENTS requirements of swine. 10.ed. Washington, DC: National Academic of Science, 1998.

PEDERSEN, C.; LINDBERG, J.E.; BOISEN, S. Determination of the dietary threonine:lysine ratio for finishing pigs using three different methods. Livest. Prod. Sci., v.82, p.233-243, 2003.

POZZA, P.C. Exigência de treonina digestivel para suínos machos castrados e fêmeas dos 15 aos 30kg. 1997. Dissertação (Mestrado) Universidade Federal de Viçosa, Viçosa, MG. $61 \mathrm{p}$.

ROSTAGNO, H.S.; ALBINO, L.F.T.; DONZELE, J.L. et al. Composição de alimentos $e$ exigências nutricionais de aves e suínos: tabelas brasileiras. Viçosa, MG: UFV, 2000. $141 \mathrm{p}$.

SALDANA, C.I.; KNABE, D.A.; OWEN, K.Q. et al. Digestible threonine requirements of starter and finisher pigs. J. Anim. Sci., v.72, p.144-150, 1994.

SCHUTTE, J.B.; DE JONG, J.; SMINK, W. et al. Threonine requirement of growing pigs (50 to $95 \mathrm{~kg}$ ) in relation to diet composition. Anim. Sci., v.64, p.155-161, 1997.

THONG, H.T.; LIEBERT, F. Potential for protein and threonine requirement of modern genotype barrows fed graded levels of protein with threonine as the limiting amino acid. $J$. Anim. Phys. Anim. Nutr., v.88, p.196-203, 2004.

SISTEMA de análises estatísticas e genéticas. SAEG. Versão 8.0.Viçosa: UFV, 2000.

ZHU, C.L.; RADEMACHER, M.; De LANGE, C.F.M. Increasing dietary pectin level reduces utilization of digestible threonine intake, but not lysine intake, for body protein deposition in growing pigs. J. Anim. Sci., v.83, p.1044-1053, 2005. 